\title{
Gamified In-Home Rehabilitation for Stroke Survivors: Analytical Review
}

\author{
Paul Tamayo-Serrano ${ }^{1}$, Samir Garbaya ${ }^{2}$, Pierre Blazevic ${ }^{3}$ \\ 1 Corresponding and First Author, 3 Laboratoire END-ICAP, U1179 INSERM, University of Versailles \\ Saint-Quentin-en-Yvelines, Versailles, 78000 - France, \{paul.tamayo-serrano, \\ pierre.blazevic\}@uvsq.fr \\ ${ }^{2}$ Laboratoire END-ICAP, U1179 INSERM, ENSAM - ParisTech, Paris, 75013 - France, \\ samir.garbaya@ensam.eu
}

\begin{abstract}
A stroke is a life-changing event that may end up as a disability, with repercussions on the patient's quality of life. Stroke rehabilitation therapies are helpful to regain some of the patient's lost functionality. However, in practice stroke patients may suffer from a gradual loss of motivation. Gamified systems are used to increase user motivation, hence, gamified elements have been implemented into stroke rehabilitation therapies in order to improve patients' engagement and adherence. This review work focuses on selecting and analyzing developed and validated gamified stroke rehabilitation systems published between 2009 and 2017 to identify the most important features of these systems. After extensive research, 32 articles have met the selection criteria, resulting in a total of 28 unique works. The works were analyzed and a total of 20 features were identified. The features are explained, making emphasis on the works that implement them extensively. Finally, a classification of features based on objectives is proposed, which was used to identify the relationships between features and implementation gaps. It was found that there is a tendency to develop low-cost solutions as in-home therapy systems and provide a variety of games. This review allowed the definition of the opportunities for future research direction such as systems addressing the three rehabilitation areas; data analytics to make decisions; motivational content identification based on automatic engagement detection and emotion recognition; and alert systems for patient's safety.
\end{abstract}

Keywords: Stroke, Rehabilitation, Virtual Reality, Gamification, Serious Games, Design Features

\section{Introduction}

Brain stroke is a life-changing disease that can have fatal consequences. Stroke survivors may end up with long-term disabilities. These disabilities will depend on the damaged part of the brain and the body functions related to it. Older adults are the population with the highest risk of suffering a stroke and ending up with a disability. This makes of stroke the leading cause of adult disability worldwide [1-4].

Stroke rehabilitation therapy has proven to be useful in helping the patient to regain some of his lost functionality [5-8]. In traditional rehabilitation programs, when the rehabilitation in the hospital is completed, the patients return to their homes, where they should continue with more rehabilitation activities. However, the patient's adherence is reduced at home. The two main causes for this are: the lack of available resources and tools to sustain training for longer periods; and, a diminishing motivation as repetitive exercises are perceived as tedious and boring [9-12]. Gamified rehabilitation systems have proven to be useful to improve motor and cognitive function and additionally as a tool to motivate patients to adhere to the therapy programme [13-22].

There is limited literature providing a comprehensive overview on the evaluation and comparison of the gamified post-stroke rehabilitation studies involving features identification. Flores et al. [15] presented a comparative assessment of 6 existing gaming scenarios and their adaptability to post-stroke motor rehabilitation therapy conducted with robot-aided interfaces to support patient's 
motivation. Flores et al. [15] introduced 14 assessment criteria to evaluate games with a particular focus on motor recovery and elderly entertainment. Lange et al. [11] approached the potentials of gamified telerehabilitation systems under the broader titles such as part-to-whole practice, motivation, low cost, interaction devices, complex packing, consistency of computer and internet capabilities, data management, technical support, privacy protection, seizure, distance trials. Lohse et al. [23] reviewed 26 studies applying VR technologies in adult post-stroke therapies by means of custom built VR environments and commercial games. Using the Physiotherapy Evidence Database Scale (PEDro) for qualitative assessment, they presented a meta-analysis of 24 studies [54]. Webster and Çelik [24] included 48 studies in total in their review regarding kinect-based serious games for elderly care and post-stroke rehabilitation. Instead of a comparison, Webster and Çelik [24] presented a broader overview with a specific focus on the significant findings of each study, apart from presenting the relevant information such as the date of the study, the age of the target group and the research type. Barrett et al. [22] compared eight video game-based systems, taxonomies and frameworks for the gamified upper-limb stroke rehabilitation, providing 28 features in total. They discussed the crucial concepts of game design such as meaningful play, feedback, goals, rewards, challenge, difficulty, failure and flow in detail and contributed a framework to map the game design concepts. Being a fundamental concept, "meaningful play" which was listed by Barrett et al. [22] as a feature was also used in the scope of our study. Different from the review articles, Hung et al. [21] presented the findings and outcomes of a survey study that revealed the perspective of the patients to the games in post-stroke rehabilitation.

Although there are some review works on gamified stroke rehabilitation systems, only few of them focused on identifying the important features for developing such systems. Among these reviews, a few analyze not only the developed systems, but also the conceptual frameworks and taxonomies. Hence, they present features that have not been achieved yet. To the best of our knowledge, the last review that focused solely on features of the developed systems, was presented in 2009 by Lange et al. [11]. Therefore, it is necessary to conduct a review focusing on identifying the features of already developed and tested gamified systems from 2009 to 2017. This work aims to shed light on the area of gamified in-home stroke rehabilitation, by presenting what has been achieved and what are the limitations of the current implementations, as well as identifying the future research directions and opportunities.

The objectives of this study are: 1) provide a literature review of the developed and tested gamified systems for in-home stroke rehabilitation, between 2009 and 2017; 2) identify and explain the most used features of these systems; 3 ) provide a simple way to classify the features, in order to identify the relationships between them and the gaps of their implementations. A total of 32 articles have met the selection criteria, which resulted in a total of 28 unique works. From analysis of these studies, a total of 20 features were identified. The remaining of this paper is structured as follows. Section 2 describes the methodology used to find the reviewed works and the database to be used, as well as the selection criteria applied to select research works. Section 3 presents the results of the analysis, with the emphasis on the importance of each feature and the works that implemented them to higher extents. An analytical point of view is discussed in Section 4, where an objective-based classification is proposed, the relationships between the features are presented and additionally, the gaps in the current systems are identified. Finally, Section 5 is dedicated for the conclusion and the future research perspectives.

\section{Method}

In order to conduct this research, relevant literature was identified through the use of Google Scholar database. Articles were located using the query: ("stroke") AND ("gamified" OR "gamification" OR "serious games") AND ("upper limb") AND ("rehabilitation" OR "therapy").

In 2009 Lange et al. [11], conducted a research work to identify the features of game-based telerehabilitation systems. The search of this literature review was restricted to articles published between 2009 and 2017 yielding to a total of 1090 articles found. In order to focus the search, the following selection criteria were applied:

- The work must focus on stroke rehabilitation,

- It has to include a gamified solution,

- It should present the important features implemented in the gamified solution,

- The developed system must be intended for in-home use,

- The developed solution must have been tested,

- The use of the developed system must be done without assistance, 
- The work must specify the hardware used,

- The work must have been cited at least once on the used database.

The selection criteria were first applied to the title and abstract of each work, if all criteria were met, the paper was added to the review. If all criteria were not met since the reading of the abstract, a screening of the text for key points and terms was conducted. Screening key points included: searching the game design section to conclude if a gamified solution was developed, if the features were explained and if the used hardware is clearly specified. Searching the experimental design allows the verification of whether the system was tested on at least one subject. The screening process for key terms consisted in using a search tool to find meaningful terms related to the criteria: the term "home" was used to find possible occurrences that pointed the intention of the work to be used at home or not; "assisted" term was used to check if the patient was able to use the system independently or with being assisted. Finally, the criteria of being cited at least once was fulfilled through the use of Google Scholar search engine.

\subsection{The identification of features}

For identifying relevant features and sub-features, a three step process was performed. In the first step, the reviewed works were thoroughly explored in search of features, which were the main focus of the study or frequently implemented in several works. In general, the research works do not explicitly declare to have a concrete feature, this is why some inferences had to be done to identify and extract the features. This step allowed the identification of a preliminary list of features. The second step consists of reviewing the related works to explore and compare the most important proposed features with those identified in the first step. This led to the identification of more distinct features. The most important features were selected and merged in the third step. As a part of this process, the features that present a lot of similarities were combined into one feature and the closely related features were grouped together under a main feature. This allowed the definition of the final features and their related sub-features. An example of this process is explained with the Data Analysis feature, which includes the sub-features of kinematic analysis and data analytics. In the first step, both kinematic analysis and data analytics were identified as features. However, since they are closely related they were grouped under the broader feature of Data Analysis.

\section{Search results}

A total of 1090 articles were identified by database search, 32 met all the criteria. After analyzing the articles, some were identified as a continuation of previous researches, hence they were classified as one work. As result, a total of 28 unique works constitute the literature reviewed. All the works were fully analyzed to find the implemented features of the gamified solution. This process allowed the identification of a list of 20 different features. These features are presented in Table 1.

Table 1. Identified features.

\begin{tabular}{c|c|c}
\hline & \multicolumn{2}{c}{ Identified Features } \\
\hline In-Home Use & Social Interaction & Simple Interaction Devices \\
\hline Cost & Variety & Adaptive Range of Motion \\
\hline Type of Rehabilitation & Quality of Interaction & Alert System \\
\hline Patient's Monitoring & Familiarity & Motivational Rewards \\
\hline Data Analysis & Focus & Engagement Detection \\
\hline Meaningful Play & Mode of Interaction & Emotion Recognition \\
\hline Feedback & Difficulty & \\
\hline
\end{tabular}

In the remaining part of this section, each feature is explained with an emphasis on the systems that implemented them extensively. Table 2, presents the published works, the implemented features and the sub-features (when available). The information of the table reveals the following most implemented features: 
- Cost: 26 studies (92\%) being low-cost solutions,

- Type of Rehabilitation: 27 studies (96\%) addressing upper-limb gross movement,

- $\quad$ Patient's Monitoring, where 23 studies (82\%) are supervised systems,

- Meaningful Play: implemented by all the 28 studies (100\%),

- Simple Interaction Devices: 20 works (71\%) using wearable, haptic or kinesthetic devices,

- Motivational Rewards: all the 28 works (100\%) implement the points system.

Regarding the analyzed works with the most implemented features: the $\mathrm{P} 4 \mathrm{H}$ project [25] and the work presented by Chen et al. [26] implemented a total of 16 features (80\%); followed by the work developed by Hussain et al. [27] with 15 implemented features (75\%); finally, Burke et al. [28], Alankus et al. [29], King et al. [18], the REWIRE project [30, 31], the Recovery Rapids project $[32,33]$ and Bower et al. [34] all of them implemented 14 features (70\%).

\subsection{In-home use}

The duration of one-to-one occupational therapy covered by the insurance is usually insufficient to meet the rehabilitation goals of treatment programme, this justifies the prescription of home exercises $[12,21,35]$. The continuation of the exercises at home is one of the main problems of rehabilitation, because the patients are not motivated to continue practicing the exercises [28, 36]. Gamified therapy systems aim at improving the patients' motivation to adhere to the rehabilitation programme at home. In-home systems have the advantage of avoiding the transportation of the patient from his home to the hospital. This advantage reduces the problems caused by geographical constraints $[11,37]$ and allows the patient to exercise comfortably at home $[11,21,38]$.

Although all of the reviewed papers described systems for in-home use, some systems were tested only in laboratory or at the hospital (57\% of total works), with future expectations of testing them at home [9, 19, 25-27, 29, 34, 36, 39-47]. Some works (14\% of total reviewed works) included in-home systems, but the patient's data must be retrieved at given intervals of time [28, 32, 33, 48, 49]. More advanced systems (29\% of total works) allow sending the patient's data remotely via internet $[18,30,31,38,50-55]$. Even when these gamified systems were developed for in-home use, $57 \%$ of them were not tested at in-home conditions. This is a major concern, since, if the systems are not tested in real conditions, possible problems of implementation and deployment might not be detected. In addition, if a system is not tested and approved for real world conditions, it might face the resistance to acceptance by the therapists and patients.

\subsection{Cost}

The objective of in-home rehabilitation gamified systems is to overcome the disadvantages of faceto-face therapy. As stated previously, one of the main problems is related to the economic viability compared to traditional in-hospital therapy [12, 21, 23, 56-58]. In order to be adopted in-home rehabilitation systems must be a low-cost solutions. As an example, in the work developed by Hung et al. [21], the therapist reported that the gamified systems available in the hospital are normally expensive, with costs ranging from \$10,000 USD to \$20,000 USD. While the patients reported that they are willing to pay from $\$ 300$ USD to $\$ 1,500$ USD. Additionally, patients reported that they want to practice game-based rehabilitation exercises at home if they are incentivizing and affordable. It is necessary that in-home rehabilitation solutions are low-cost and that's the reason why some research works focused on using cheap solutions that are relatively easy to acquire by patients. Researchers have found that commercially available hardware designed for entertainment can be used to this end, as they are cheap and usually available in the market [21, 38, 59-61]. Most of the reviewed works comply with being low-cost solutions (93\% of total works), only the works [36] and [55] (7\% of total works) make use of high-cost virtual reality hardware. After analyzing the reviewed studies, it is clear that the researches on gamified post-stroke rehabilitation systems tend to be lowcost solutions. This tendency probably is driven by the need for developing systems that are not useful for research only but also as real-world tools for rehabilitation. It is expected that low-cost solutions would promote the adoption of in-home rehabilitation systems by patients and health organizations. 
Table 2. The research works with their corresponding features.

\begin{tabular}{|c|c|c|c|c|c|c|c|c|c|c|}
\hline$\underset{\Xi}{\mathscr{\Xi}}$ & 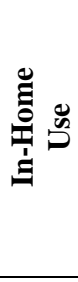 & $\dot{\tilde{g}}$ & שֶ. & 先 & 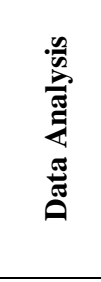 & 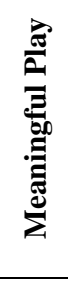 & 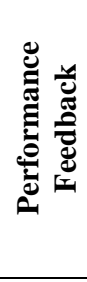 & 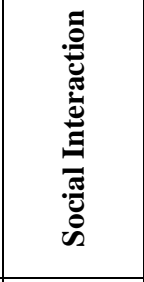 & 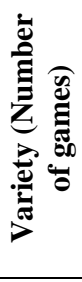 & 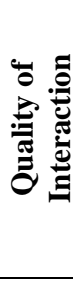 \\
\hline$[28]$ & Yes & LC & UG & FS & & Yes & Yes & & 3 & Int. \\
\hline [55] & Yes & $\mathrm{E}$ & UG & FS & & Yes & No & & 1 & \\
\hline [29] & No & $\mathrm{LC}$ & UG,UF & FS & & Yes & No & Multiplayer & 9 & Int. \\
\hline [42] & No & $\mathrm{LC}$ & UG & FS & & Yes & No & & 1 & \\
\hline [44] & No & LC & UG & FS & & Yes & No & & 1 & \\
\hline [45] & No & LC & UG,UF & FS & & Yes & No & & 1 & Int. \\
\hline$[38]$ & Yes & LC & UG & SS & $\mathrm{KA}$ & Yes & No & & 1 & \\
\hline [25] & No & LC & UG,UF,L & FS & & Yes & Yes & & 3 & Int. \\
\hline$[18]$ & Yes & $\mathrm{LC}$ & UG,UF & $\mathrm{U}$ & & Yes & No & & 9 & Int. \\
\hline$[30,31]$ & Yes & LC & UG,UF,L & SS & & Yes & Yes & Sharing & 2 & Int. \\
\hline [9] & No & LC & UG,UF & FS & & Yes & No & & 1 & Int. \\
\hline [46] & No & LC & UG,UF & FS & & Yes & Yes & & 3 & Int. \\
\hline [47] & No & LC & UG & FS & & Yes & No & & 1 & \\
\hline$[52]$ & Yes & LC & UG & SS & & Yes & No & & 1 & \\
\hline [19] & No & LC & UG & FS & $\mathrm{KA}$ & Yes & No & & 3 & Int. \\
\hline$[39,40]$ & No & $\mathrm{LC}$ & $\mathrm{UG}, \mathrm{C}$ & FS & & Yes & Yes & & 1 & \\
\hline$[36]$ & No & $\mathrm{E}$ & UG,UF & FS & & Yes & Yes & & 1 & Int. \\
\hline$[32,33]$ & Yes & LC & UG,UF & $\mathrm{U}$ & KA,DA & Yes & Yes & & 1 & \\
\hline [49] & Yes & LC & UG & SS & $\mathrm{KA}$ & Yes & Yes & & 1 & \\
\hline [26] & No & LC & UG & FS & $\mathrm{KA}$ & Yes & Yes & & 3 & Int. \\
\hline$[50,51]$ & Yes & LC & UG,UF & SS & $\mathrm{KA}$ & Yes & No & & 5 & Int. \\
\hline [53] & Yes & $\mathrm{LC}$ & UF & $\mathrm{U}$ & & Yes & Yes & & 3 & \\
\hline [34] & No & LC & UG,L & FS & & Yes & Yes & & 4 & Int. \\
\hline [41] & No & LC & $\mathrm{UG}, \mathrm{C}$ & FS & & Yes & No & & 1 & \\
\hline [43] & No & LC & UG & FS & & Yes & Yes & & 1 & \\
\hline [48] & Yes & LC & UG,UF,C & $\mathrm{U}$ & & Yes & No & & 1 & Int. \\
\hline [54] & Yes & LC & UG & $\mathrm{U}$ & $\mathrm{KA}$ & Yes & No & & 2 & Int. \\
\hline [27] & No & $\mathrm{LC}$ & UG,UF & FS & KA & Yes & No & & 2 & \\
\hline
\end{tabular}

Abbreviations: LC: Low-cost; E: Expensive; UG: Upper-limb gross movement; UF: Upper-limb fine movement; L: Lower-limb; C: Cognitive; FS: Fully-supervised; SS: Semi-supervised; U: Unsupervised; KA: Kinematic analysis; DA: Data analytics; Int.: Intuitive. 


\begin{tabular}{|c|c|c|c|c|c|c|c|c|c|c|}
\hline Works & 氖 & 号 & 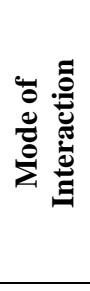 & 总 & 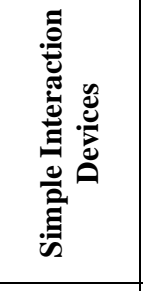 & 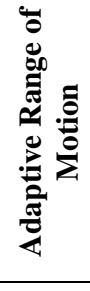 & 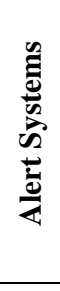 & 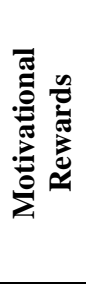 & 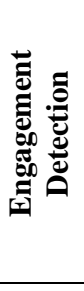 & 串 \\
\hline [28] & & & & A & VB & Non-A & & Yes & Yes & Yes \\
\hline [55] & & & & & Others & & & Yes & & \\
\hline [29] & Yes & & & Non-A & $\mathrm{VB}+$ Others & & Yes & Yes & & Yes \\
\hline [42] & & & & & Others & & & Yes & & Yes \\
\hline [44] & & & & & Others & & & Yes & & \\
\hline [45] & & & & & $\mathrm{VB}+$ Others & & & Yes & & \\
\hline [38] & & & & & $\mathrm{VB}+$ Others & & & Yes & & \\
\hline [25] & Yes & $\mathrm{AF}$ & & Non-A & $\mathrm{VB}+$ Others & & Yes & Yes & Yes & Yes \\
\hline [18] & Yes & $\mathrm{AF}$ & UD & & Others & & & Yes & Yes & Yes \\
\hline$[30,31]$ & & & & A & $\mathrm{VB}+$ Others & A & Yes & Yes & & \\
\hline [9] & & & & A & Others & & & Yes & & Yes \\
\hline [46] & & & & Non-A & $\mathrm{VB}+$ Others & & & Yes & & \\
\hline [47] & & & & & VB & & & Yes & & \\
\hline [52] & & & & Non-A & Others & & & Yes & & \\
\hline [19] & & & & Non-A & Others & & & Yes & & Yes \\
\hline$[39,40]$ & & $\mathrm{AF}$ & UD & Non-A & Others & & & Yes & Yes & Yes \\
\hline [36] & Yes & & & Non-A & Others & & & Yes & & Yes \\
\hline$[32,33]$ & & & UD & Non-A & $\mathrm{VB}+$ Others & A & & Yes & Yes & Yes \\
\hline [49] & & & & Non-A & Others & & & Yes & & \\
\hline [26] & Yes & $\mathrm{AF}$ & & Non-A & VB & & Yes & Yes & & Yes \\
\hline$[50,51]$ & Yes & & UD & Non-A & VB & & & Yes & & \\
\hline [53] & & & & Non-A & Others & Non-A & & Yes & Yes & \\
\hline [34] & Yes & & & Non-A & VB & & & Yes & Yes & Yes \\
\hline [41] & Yes & & & A & VB & & & Yes & & \\
\hline [43] & & & & & VB & & & Yes & & Yes \\
\hline [48] & Yes & & & & Others & Non-A & & Yes & Yes & Yes \\
\hline [54] & & & UD & A & Others & A & Yes & Yes & & \\
\hline [27] & Yes & $\mathrm{AF}$ & & A & Others & Non-A & & Yes & & Yes \\
\hline
\end{tabular}

Abbreviations: AF: Age-focused; UD: User-driven; A: Automatic; Non-A: Non-Automatic; VB: Visionbased. 


\subsection{Type of rehabilitation}

Prior to developing a gamified rehabilitation system, it is necessary to define the type of disabilities to be addressed. For rehabilitation, there are two categories: Cognitive and Physical/Motor [17]. For stroke rehabilitation, motor area divides into two sub-areas, thus stroke rehabilitation systems are classified into three main areas: upper limb, lower limb and cognitive.

Given that this review focuses on upper limb rehabilitation systems, all the reviewed works address this type of rehabilitation. Upper limb rehabilitation works were focused on gross and fine movements. The research works concerned only by the gross movement of the patient's arms and hand's positioning, which mobility is basic for achieving the first steps of the patient's independence are: $[19,26,28,34,38,41-44,47,49,52,54,55]$ (50\% of total works). After achieving the gross movement of arms, the next priority is to achieve finer daily life task related exercises such as hand closing/opening [18, 29-31, 45, 50, 51] (14\% of total works), pinching, grasping and moving objects $[9,25,27,29,32,33,36,46,48,50,51,53]$ (36\% of total works).

In addition to the upper limb, some works addressed lower limb rehabilitation. They focused on balance and gait which were measured by using Nintendo's Wii Balance Board TM, as reported in the REWIRE project [30, 31] and $\mathrm{P} 4 \mathrm{H}$ project [25].

The cognitive aspects were addressed by RehabCity [39, 40], it focused on the rehabilitation of the patient's memory and the ability to follow instructions in a simulated environment of daily life activities. Kirk et al. developed an interesting work that includes cognitive rehabilitation [48]. Their work allows the patient to use his/her upper limbs to solve cognitive tasks. Music was used as a mean to help and motivate the patient to solve the cognitive task. In their research, they found that stroke survivors reported high levels of motivation to use music as part of their rehabilitation.

The project Reh@Task [41], allows measuring the rehabilitation impact of combined cognitive and motor rehabilitation. Although the results showed higher motor improvements on the control group, the authors theorize that it may be that the intervention of the control group targeted more generalized motor rehabilitation, whereas the experimental group targeted simple gross reaching movements only, thus limiting the effectiveness of the motor rehabilitation.

All the 28 reviewed works addressed upper limb rehabilitation, but only three of them $(10 \%$ of total works) focused on lower-limb. Another three works (10\% of total works) targeted cognitive rehabilitation. It is important to note that none of them addressed the three rehabilitation areas simultaneously. A system that is able to target these three areas could be a good solution, as it could handle a wide spectrum of stroke patients.

\subsection{Patient's monitoring}

The objective of a gamified rehabilitation system is to improve the patient's rehabilitation process and assist the therapist in making decisions about the execution of the treatment programme. In order to achieve the latter, monitoring the patient progress must be embedded in the system. As pointed out by Hung et al. [21], the exercises must be continuously tracked and therapeutic suggestions and corrections must be made. This feature, either locally or remotely, must be integrated into the gamified rehabilitation system. In the reviewed works, patient's monitoring was divided into two groups: supervised and unsupervised.

Supervised monitoring allows the therapist checking on the patient during the execution of the exercises. This allows the therapist correcting the patient's movements or providing him with feedbacks at the moment when executing the excercices. In the cases where the gamified rehabilitation is performed at the hospital, the therapist is close to the patient. However, in remote gamified therapy, the therapist will be monitoring the patient's activities through a dashboard displaying the rehabilitation data using visual analytics. The therapist will receive data generated by the patient's activities, this data might be video transmissions, in-game scores, sensors captured data, etc. The communication link between the therapist and the patient can be constant (fully supervised), allowing the supervision of only one patient at a time; or it can be shared (semi-supervised) so that the therapist can supervise many patients at the same time. He can make a direct communication with patients as needed [2, 10, 37].

Regarding to safety and commodity, most of the reviewed works (64\% of total works) are fully supervised $[9,19,25-29,34,36,39-47,55]$. They range from systems that are used in the hospital with the therapist next to the patient, to full in-home systems with allowing the therapist to have constant remote-video communication with the patient. Semi-supervised systems (18\% of total works) range from at-hospital systems that need minimal therapist intervention, to in-home systems 
that allow opening a communication channel between the therapist and the patient $[30,31,38,49$ 52].

Unsupervised monitoring consists of using a gamified system that does not require the physical presence of the therapist, neither on his remote workstation to monitor the patient's performance. Unsupervised monitoring relies on capturing the patient's data which can be analyzed later by the therapist. As stated by [10] and [21], the feature of reporting back the patient's progress to the therapist is essential for home rehabilitation. It was noted that the patients worry about whether their rehabilitation exercises are being performed correctly, particularly when they are not supervised by the therapist. Unsupervised monitoring allows the patient more freedom to choose the time to practice the exercises, he is not constrained by the therapist's working hours. The number of fully unsupervised systems (18\% of total works) is less than supervised systems, yet some examples exist $[18,32,33,48,53,54]$.

Although the ultimate goal of in-home stroke rehabilitation systems could be to allow complete unsupervised monitoring, safety is a major concern. This concern is reflected in the number of works that are fully supervised (64\%). As mentioned previously, fully supervised systems have several advantages, but requiring the full time presence of the therapist reduces their efficiency in some aspects. In-home stroke rehabilitation systems need to advance in the direction of fully automated and unsupervised systems where they can achieve their utmost potential. For this reason, semi-supervised systems might be the middle-ground solution to convince the therapists and patients to accept the transition from fully supervised to fully unsupervised systems.

\subsection{Data analysis}

Data capture and analysis allows the therapist making decisions on the execution of the rehabilitation programme. The possibility of performing accurate motor and cognitive recovery assessments plays critical role in the rehabilitation process of stroke patients [62]. Traditionally, the patient's performance is monitored by the therapist during the exercises, the summary of the performance scores are obtained at the end of rehabilitation sessions. The performance is measured thanks to the use of standard clinical rate scales (e.g.: Motor Activity Log (MAL), Barthel index for ADL, FuglMeyer Assessment of Motor Recovery after Stroke (FMA), Stroke Impact Scale (SIS), Wolf Motor Function Test (WMFT), Chedoke Arm and Hand Activity Inventory (CAHAI)). This information allows the therapist making the decision to continue or adapt the therapy to the actual performance of the patient. However, this approach relies on the observations of the therapist and the used measures. Since this is not an automatic standardized process and it is dependent on the therapist's perception, the accuracy of the assessments can be heavily influenced by his/her subjective judgment [62].

With the inclusion of new technologies to therapy processes, it is possible to capture more data, even hidden data that a single therapist is unable to capture [63]. Moreover, it is possible to capture data from multiple patients at the same time [62]. Data capture helps in both supervised and unsupervised systems. In supervised systems, the data captured by sensors attached to the patient will provide more information about his medical conditions. This information can be useful to the therapist to make a better decision about the patient. Data capture and analysis is more important in unsupervised therapy, it is performed automatically by the rehabilitation system. After being processed the data is presented to the therapist for assistance on planning the therapy programme and decision making. Thus, the system itself becomes an assistant for the therapist $[62,63]$.

In the reviewed works, the most common data analyzed are the kinematic data generated by the patient's limbs movement ( $28 \%$ of total works). These data are used to search for a correlation between kinematic performance and scores in standard clinical rating scales. If an increase in kinematic performance and better scores in the clinical rate scales are found, then the result of the evaluation states that the system helps in the rehabilitation process, as described in $[19,26,27,32$, $33,38,49-51]$. In order to apply these standard clinical test, the presence of the therapist is required, this represents the disadvantage of these systems. This process is time-consuming and justifies the need for the development of automatic in-game assessment [49].

A more complex but helpful implementation of data analysis is presented by Golby et al. [38] and Wittmann et al. [54]. They implemented kinematic analysis for automatic evaluation that allows making a correlation between the patients' generated data and the result of standard clinical rehabilitation tests. This implementation provides considerable aid to the therapist, since he is free from making these tests himself, hence he/she can attend more patients or focus on patients with special needs [49]. Serradilla et al. [49], implemented the same feature in a system they developed. Their approach allows performing automatic in-game assessment to a clinical standard. Their system 
was able to apply the CAHAI in a shortened version known as CAHAI-10. The results were positive, to the point that it allowed them to claim that their work is the first that allows automatic in-game assessment at clinical level using low-cost solution. Although the concept was developed and tested, the only possible problem with this work is that it was tested with only 3 sensors, which limits the possible movements that can be captured and analyzed.

Another possible implementation of data analysis feature is data analytics that presents to the therapist knowledge extracted from the patient's data. The therapist can take a well-informed decision on the future course of patient's therapy. Data must be processed for patterns extraction for one or many patients. The correlation between different variables identifies the causes of improvement or complications that must be detected and the prediction of the future patterns can be made. Moreover, knowledge extraction could allow determining which therapy focus is better for patients with similar profiles, thus ensuring better recovery for future patients based on the history of performance records. This feature will provide the therapist with suggestions on how the patient's therapy should be addressed, hence helping the therapist to take a well-informed decision about his patients $[64,65]$. Recovery Rapids project $[32,33]$ is the only research of the reviewed works that present data analytics approach to evaluate the patient's performance. As a positive outcome of their analysis, they found a hidden pattern on the patient's performance leading to the conclusion of the presence of tiredness of the patient.

Among all the reviewed works, only the Recovery Rapids project (3\%) implemented data analytics $[32,33]$. The authors made the emphasis on how this feature is helpful to discover new information and demonstrated it by identifying the fatigue of the user. Even though, this work implemented this feature perfectly, the system must send online data at distance to make this feature more effective. The data can be processed and presented instantly to the therapist for decisionmaking. Therefore, the instant online data analytics from multiple patients is a system feature that is still not developed despite its high potential.

\subsection{Meaningful play and feedback}

The concept of meaningful play is one of the most crucial features for video-games which has been discussed by various scholars [22, 26, 28, 36, 66]. Creation of meaningful play has potential to lead successful games [67]. In order to achieve meaning in games, a feedback mechanism between the player and the actions has to be implemented. The player needs to perceive the immediate effects of his/her actions that must have an impact in the game at some point in the future. By the decisions and the actions made by the player, he/she will shape the outcomes of the game [67].

The game feedback informs the player about the result of his/her actions. The feedback feature provides extra stimulus that are not easily delivered in the real world. Hence, cues or hints can be given to the patient prior to a response in order to help him to be guided in achieving a successful performance of actions [68, 69]. The feedback is necessary as it gives a notion that the actions of the player will affect the virtual world of the game in positive or negative ways. The feedback can show negative outcomes of actions, it must be presented in a positive and encouraging way so that the patient won't get discouraged [24].

The game must have a mean of showing the player the advantages and disadvantages of taking successful and unsuccessful actions. In the case that the relationship between the actions and the results is not provided, it might diminish the engagement of the player. Positive feedback on successful actions is necessary so that the player can perceive that their actions are executed as expected. This kind of positive reinforcement will encourage the player to keep going forward in the game [22, 69]. Negative feedback for unsuccessful actions can motivate the player to change his current actions to achieve success in the task at hand. The lack of negative feedback can lead to frustration because the player will not understand his errors and why he can't progress in the game [22, 69].

For stroke rehabilitation games, due to possible cognitive problems of the patient, more notorious feedback must be supplied. This can include verbal encouragement, points, charts, or a video replay. This is beneficial to the patient as cognitive impairments can be present even if the main objective is to recover motor functionality $[15,22]$. It is important to note that appropriate feedback can be for both patient and therapist. The therapist's feedback is used to determine how well the patient is improving and can be used to provide some encouragement to the patient to adhere to the therapy. Visual feedback such as graphs of patient's performance on a given time can be useful for the therapist, it illustrates the improvement of the patient and allows to define the planning of the therapy sessions [15]. 
Regarding meaningful play, all the works reviewed complied with the definition, they have some means of feeding back information on actions to the patient, hence giving sense to the performed actions.

Apart from the feedback on actions executed by the patient, the works [25, 26, 28, 30-34, $36,39,40,43,46,49,53$ ] ( $42 \%$ of total works), presented feedbacks that explicitly allow the patient to know how he/she is performing during and at the end of the game sessions. This in-game feedback presents hints or cues that indicate to the player the correct moves to execute and if they are performing correctly. After the game session, the feedback is usually shown as a graph where the player can easily see his/her previous and current performance, hence informing him/her about the progress over time.

Although feedback is mainly used to motivate the patients, it can also help the therapist to monitor their performance. Furthermore, as shown by the number of works implementing this feature $(42 \%$ of total works), feedback can be used to better support the execution of exercises. It can be implemented to inform the patients about the correctness of their movements and if necessary, providing them with hints on how to rectify the movements [26, 36, 69].

\subsection{Social interaction}

Social interaction is a powerful motivational feature. It is considered as the most important motivational aspect to be implemented in a rehabilitation system [22]. In fact, social interaction has been used widely and successfully in the video-game entertainment industry to engage players. Being able to share his progress with other people and earning some acknowledge is an important part of human's nature. Even more, social interaction usually allows the players to friendly cooperate or compete among themselves. Competition being a strong conduct as most of the humans strive to show that they are better than another, if not the best of all [24]. By providing social interaction, patients can share their progress with family, friends, or other patients. This is important since some patients go to the hospital just for the social support that the environment provides during the therapy sessions [21]. Thus facilitating social support becomes a source of motivation for the patient to adhere to the rehabilitation exercises $[15,70]$.

The simplest implementation of social interaction in gamified rehabilitation is to share the patient's score and progress with other players, so they could congratulate each other, thus increasing motivation. This feature is included in the REWIRE project $[30,31]$ as one of their motivational features.

As previously mentioned, multiplayer interaction is a very powerful motivational tool. Multiplayer can be divided in cooperative where the players cooperate to reach a common objective and competitive where players compete among themselves. Alankus et al. [29] went further by allowing social interaction by enabling cooperative and competitive multiplayer modes. For cooperative mode, the patient can play with another relative or a friend. If the patient is alone at home, a computer player is provided to help him complete the necessary tasks. The competitive aspect of their work allows the two players to interact with the objects, earning points and comparing the score to determine the winner.

From a theoretical perspective it has been indicated that social interaction can be very useful for motivating the users. Nevertheless, only few of the reviewed works have implemented this feature ( $7 \%$ of total works). This might be due to the lack of considering the potential of incorporating social interaction as a mean to increase the effectiveness of the therapy.

\subsection{Variety}

Well-designed games can motivate patients to play while supporting the possibility of engagement. Therefore in well-designed games, the sense of joy replaces the notion of being in therapy [11]. People might get easily bored from any repetitive action and the routinary games. However, the perceived fun influences players' adherence during the gameplay. Players tend to play games multiple times if the experience of the game is pleasant. Thus, in order to keep patients engaged, the game has to be enjoyable, otherwise, they might stop playing. As a consequence, their rehabilitation exercises would be interrupted. Doing the same activity many times or playing the same game constantly might be tiring and boring for the patient. Hence, gamified solutions must include motivational aspects to avoid repetitiveness [26].

Since, what is perceived as a pleasant game for a person might not be perceived as fun for another, making one game fun for everybody may be an almost impossible task. It is more convenient to provide different games or mini-games for the patient and let him/her choose the appropriate 
game. The bigger the catalog of possible games, the higher will be the changes for providing fun games for a broader range of patients [65]. This is confirmed by the study that has been carried out by Hung et al. [21], where $76 \%$ of the patients pointed out that their gamified rehabilitation system would be better if more diverse games were provided.

Most of the reviewed works implemented only one game (54\% of total works) in order to prove the concept developed in their work. In some cases they have two games $[27,30,31,54](10 \%$ of total works), three games [19, 25, 26, 28, 46, 53] (21\% of total works), four games [34] (4\% of total works), five games [50, 51] (4\% of total works), and even nine games [18, 29] (7\% of total works). Alankus et al. [29], tested nine games to explore the space of games that can be used for stroke rehabilitation systems. Hence, their games not only are different in themes, rules and objectives but additionally they tested the impact of three main attributes: social context, motion type and cognitive challenge. This helped them to find which games attributes and to what extent they are appropriate and preferred by stroke patients.

The number of reviewed works implementing just a single game $(54 \%)$ is relatively similar to the number of studies presenting a variety of games (46\%), from which $36 \%$ have implemented three or more games.

\subsection{Quality of Interaction and familiarity}

Rehabilitation games must be easy enough for the users to understand, interact and achieve the required goals [16]. As explained by Hung et al. [21], complex interactions such as several elements to select at the same time, small elements on display, a great number of hard to remember rules may lead to the situation of cognitive overload, which prevents the progress and reduces the adherence of the patient. The factors which affect adherence to a game are considered as subjective aspects that might differ from one player to another. That is why the games require tests by involving different user groups prior to their release. Nevertheless, there might be some extent of correlations among the games which consist of similar gameplay in terms of user preferences and tendencies. In their study, Hung et al. [21] introduced that $84 \%$ of the therapists agreed that if a gameplay is similar to a prior game experience of the patients, the familiarity with the game is thought to positively influence the patient's motivation for rehabilitation.

Intuitiveness plays a crucial role in patients' perceived quality of interaction, via allowing users to adapt to the game interface, learn and remember the rules of the game easily. Studies in the literature show that the games including rules that are already known by the patients have a higher acceptance rate [15]. Elderly players appear to prefer simple games or easy games which can be learned in a short period of time. Moreover, elderly players prefer thought-based games such as a history and work trivia [15]. Examining the tendency and preferences of the elder people is important for future game developers in the context of stroke rehabilitation.

In the reviewed works, several systems succeeded to be intuitive and therefore having a good quality of interaction. This mostly thanks to being mini-games or casual games developed or adapted for rehabilitation, where there are only a few easy to understand rules and the interaction is very simple to achieve. The works $[9,18,19,25,26,28-31,34,36,45,46,48,54](53 \%$ of total works), all include at least one game that complies with the definition of being intuitive. Familiarity is implemented in the works [18, 25-27, 29, 34, 36, 41, 48, 50, 51] (35\% of total works). Reh@ Task [41] presents a gamified version of a paper-based cognitive exam. Since the patients are familiar with the paper version of the exam and the gamified version is not different in content, the gamified version is considered to achieve familiarity. Classic infancy games are good options for familiar games as their enjoyment and rules are already known. They are recurrently implemented as minigames such as: Labyrinths [25, 34, 36], Puzzles [36, 52, 53], Baseball [29], Mah-Jong [18], Solitaire [18], Memory [27] and classic video-games [18, 29]. In addition, another recurrent familiar implementation is the gamified experience of gardening [26, 29]. Kirk et al. [48], achieved familiarity by implementing a drummer experience in the game they developed. In addition, the patient can select the music that he likes to be used in the game, which was reported as a much-liked feature of the system.

Quality of interaction can be enhanced by several means, although the present review identified the aspect of intuitiveness only which was implemented in $53 \%$ of the reviewed works. Familiarity was addressed by $35 \%$ of the reviewed works, in all these studies, patients stated that they enjoyed practicing the rehabilitation activities that are related to their prior experiences. 


\subsection{Focus and Mode of Interaction}

Gamified training helps elder people to be more motivated and confident [71]. Stroke rehabilitation games most likely will be dedicated to older-aged patients as they are the most prone population to suffer from a stroke. As there are differences in how individuals perceive a game to be pleasant, their perception can also vary with age. The games that a child considers to be fun might not necessarily be perceived as fun by older people. Additionally, as older people usually have slower reaction times and even more for stroke patients, the games' pace must be adapted accordingly [15, 28]. In the study carried out by Hung et al. [21], 18 out of 19 therapists suggested that to make gamified systems more serviceable for patients at every stage of recovery, specific games must be developed for different ages. Hence, for stroke survivors' rehabilitation therapy it is preferred to develop user-driven games (where the player takes the initiative and the gameplay is not restricted in time) than rapid-paced games that require an instant response and fast movements from the patient. This is one reason why most off-the-shelf games are not suitable for stroke patients, as they are created for healthy people whose movements are faster than stroke patients $[28,54,60]$.

The reviewed works that provided an age-focused experience for stroke patients are: [18, $25-27,39,40]$ ( $18 \%$ of total works). User-driven interaction mode was implemented in the works $[18,27,32,33,39,40,50,51]$ (18\% of total works). User-driven interaction mode might cause the gameplay sessions to become too time consuming and boring for the patients, thus it is used only in games where time is not important factor, as in the case for turn-based games [18, 27, 50, 51]. Some systems such as the project Recovery Rapids [32,33] are divided into parts: user-driven experience and time-dependent experience. Finally, RehabCity $[39,40]$ allows the patients to perform as many activities and challenges as possible in a time span of 20 minutes, but doesn't pressure them, so they can perform the activities at their own pace.

Each of these two features have been implemented in only $18 \%$ of the reviewed studies. However, it is important to consider the characteristics of the target group, especially for older stroke survivors which have their own needs and limitations.

\subsection{Difficulty}

The difficulty is a way of motivating and engaging the player, but if used incorrectly, it generates demotivation, frustration and desertion. Setting the correct difficulty in a game is a very active area of investigation [72-79]. The idea behind difficulty, which is detailed in [80], is to provide adequate challenge to the player. Without a challenge, the player is bored and abandons the play, but with facing a very big challenge he/she becomes frustrated and might stop using the game. The ideal degree of difficulty is a midpoint where the player stays interested and the challenge can be completed.

Smeddinck et al. [76], presented three main difficulty groups: difficulty selected by menu, Automatic or Dynamic Difficulty Adjustments (DDA) and embedded selection. Difficulty selection by menus is the classic implementation that includes presets such as "easy", "medium" and "hard". The player (or the therapist) can select the level to be attempted. Automatic selection will analyze the actions of the player and constantly adapts the difficulty parameters to meet the current level of performance of the player, consequently, the aspect of challenge is maintained. Embedded difficulty consists of presenting to the player in-game decisions that will affect the game's difficulty, the player will choose them (sometimes without being aware of choosing) and based on that selection, in-game parameters will be increased or decreased. For stroke rehabilitation, automatic adaptive difficulty may seem like the best possible solution, since it can address a wide population of patients with different needs. Moreover, it complies with the requirement that games should have a level of difficulty but it should not exceed the ability of the patients, thus avoiding the games being too aggressive or generate discomfort [60].

The reviewed works $[19,25,26,29,32-34,36,39,40,46,49-53]$ (46\% of total works), include a predefined difficulty in the form of menus or levels with a progressive difficulty. The difficulty is static at a given moment while setting the correct level of difficulty is the responsibility of the therapist. In the reviewed works that implemented this feature $[9,27,28,41,54](18 \%$ of total works), the automatic adaptation is made after every game session. One of the most advanced works that has implemented adaptive difficulty in gamified stroke rehabilitation systems is the REWIRE project $[30,31]$. In their work, they achieved the constant adaptation of difficulty throughout the game session, which means that difficulty is adapted to the player's performance at the same moment of playing the game. The algorithm allows the therapist to change the desired difficulty settings; so the patient could always achieve a prefixed level of success. 
For stroke rehabilitation, automatic adaptive difficulty seems to be the best answer, as it will adjust to each patient's performance. Nevertheless, implementing an algorithm for precisely adapting to each possible need might be a complicated task, as demonstrated by the small number of works that have implemented it (21\% of total works). Moreover, constant in-game difficulty adaptation is harder to achieve as it was developed by only one work among the reviewed researches ( $3 \%$ of total works). It is also important to investigate whether automatic adaptive difficulty is better than non-automatic adaptation. In the work developed by Smeddinck et al. [76], two experiments were carried out, they found that for casual games, all types of adaptive difficulties produce relatively similar level of player enjoyment and motivation. In the context of rehabilitation, it can also be investigated whether the type of adaptive difficulty can have a significant impact on patients' rehabilitation and to see if it would be better to develop a hybrid approach combining manual and automatic difficulty adjustment. This proposed hybrid approach could start with a classic menu, where the therapist can set the initial difficulty level by manually specifying each variable and then, an automatic algorithm can adjust those variables according to the current performance of the patient. Thus, the therapist would have control over the difficulty level of the patients' therapy and the automatic adaptive difficulty will be tuning up the details of the chosen preset during the therapy session.

\subsection{Simple interaction devices}

When selecting the interface hardware dedicated to the patient, the cost is not the only issue to consider. The usability of the interaction devices must be taken into account, particularly for older people who may struggle with learning to use complex interfaces. Moreover, due to the limitations caused by stroke, it is not guaranteed that the survivors will be able to use or even hold a complex device. Wearable devices such as: electromagnetic sensors, data gloves and HDMs have the drawback of needing to be attached or fixed to the user, which can be problematic and even a burden for users with physical impairments [28, 29, 53, 60, 68, 81].

To address these problems for stroke patients, Natural User Interfaces (NUI) are recommended. NUIs are devices that capture the natural real-life movements of the user and transform them to actions in a computational system. Their objective is to enable the users to effectively use their body as controllers. NUIs aren't just convenient, as the learning curve for using them is small, but additionally they tend to be engaging because using the body to control a game gives the user a greater sense of participation [60,82].

Vision-based NUIs are very appealing as they are usually easy to configure and operate and not intrusive [28]. To operate vision-based NUIs, the user have to be in the effective range of vision of the interface [28]. Microsoft's Kinect ${ }^{\mathrm{TM}}$ with its affordable price and adequate features is one of the most widely used vision-based NUIs for gross movement capturing and interaction. Tanaka et al. [61] compared three commercial low-cost motion capture devices used in rehabilitation systems: the Sony PlayStation Move, Nintendo Wii and Microsoft's Kinect ${ }^{\mathrm{TM}}$. They concluded that for rehabilitative purposes Kinect ${ }^{\mathrm{TM}}$ is the best NUI. Furthermore, several studies have compared the accuracy of Kinect ${ }^{\mathrm{TM}}$ against more expensive motion capture hardware. The results showed that Kinect $^{\mathrm{TM}}$ is a reliable tool for gross movement when affordance is a major problem [59, 83-87]. However, it is necessary to mention that Kinect ${ }^{\mathrm{TM}}$ and vision-based movement detection systems are affected by occlusion, which limits the range of user's movements that can be detected. In addition, Kinect $^{\mathrm{TM}}$ lacks the precision for capturing fine movements; however, combining it with inertial sensors can be a feasible solution to this problem [24].

In the reviewed works for gross movement, vision-based low-cost hardware such as cameras web $[25,28,29,41]$ (14\% of total works), PrimeSense's Carmine ${ }^{\mathrm{TM}}$ [34] (3\% of total works) and $\operatorname{Kinect}^{\mathrm{TM}}[25,26,30-33,38,43,45-47,50,51]$ (35\% of total works) were the most used interaction devices. Another recurrently used low-cost hardware was Nintendo's Wiimote ${ }^{\mathrm{TM}}[18,25$, $29,42,44,53]$ ( $21 \%$ of total works). For lower limb balance, the most used low-cost solution was Nintendo's Wii Balance Board ${ }^{\mathrm{TM}}[25,30,31]$ (7\% of total works). For fine hand and finger movement capturing, data gloves were used [32, 33, 45, 46, 53] (14\% of total works), although because of the added burden, some of those works did not recommend these kind of devices for stroke patients. Therefore, a more intuitive and less cumbersome option such as Leap Motion ${ }^{\mathrm{TM}}$ can be used [50, 51] (3\% of total works). Some studies have utilized haptic devices which have the advantage of providing extra feedback to the patient; however they must be worn or held by the user which is constraining [30, 31, 36, 52] (10\% of total works). Finally, some other works used inertial measurement units $[19,38,49,54]$ (14\% of total works), tablets [9, 48] (7\% of total works), dancing floors [25] (3\% of total works), electromagnetic trackers [55] (3\% of total works), force-sensitive 
tabletop [27] (3\% of total works) and daily life objects [9, 48] (7\% of total works). Among the reviewed works, Kinect ${ }^{\mathrm{TM}}$ and Nintendo's Wiimote ${ }^{\mathrm{TM}}$ were the most used devices $(35 \%$ and $20 \%$ respectively). This supports the literature claiming the existence of a tendency for repurposing commercially available low-cost hardware for gamified stroke rehabilitation systems.

\subsection{Adaptive range of motion}

The final objective of the gamified rehabilitation therapy is the recovery of the patient's capabilities prior to the stroke. As the patient progresses in his therapy, the range of motion (ROM) of his paretic limb is expected to increase. More exercises lead to some improvements regarding the strength, speed and range; however it is necessary to progressively push the patients to their limits in order to reach their maximal recovery. Hence, it is essential for the rehabilitation games to be adapted to the degrees of the patients' impairments and their improvements in the range of motion [15, 68].

The stroke survivors' most prevalent problem is the reduction in their limbs' range of motion. For this reason, gamified rehabilitation approaches must consider the patient's limited range of motion and adapt the game to the capabilities of the user [28]. Otherwise, similar to having excessive difficulty, it can cause negative emotions such as frustration and demotivation [54].

For adapting the range of motion of a patient, two options are available. First, there exist the non-automatic adaptation to the patient's ROM. This implementation is relatively simple and effective. As the patient progresses with the therapy, the therapist acknowledges this improvement and sets the gamified interaction objects further away. Hence, the patient has to exert a bigger motion in order to reach the interaction objects. The works that implement this feature are $[27,28,48,53]$ ( $14 \%$ of total works). The second and more appealing implementation is the automatic adaptation to the patient's ROM. In this implementation, the system automatically detects the range that the patient can exert and adjusts the in-game parameters to it. Some of the reviewed works have achieved to develop automatic ROM adaptation [30-33, 54] (10\% of total works). The REWIRE project [30, 31] has the best implementation, unlike other works, it does not just automatically adapt the ROM after each game session, but additionally it is able to adapt itself during the game session.

The literature and therapeutic practice support the need for adapting the rehabilitative activities to patients' range of motion. However, this was implemented only in $24 \%$ of the reviewed works. Nevertheless, in these few works, adaptive range of motion was well received by the therapists, as it allowed them tailoring the system to specific patient's needs and limitations.

\subsection{Alert system}

Although the increase in the range of movements of the patient is the goal of physical therapy, extra care should be put in avoiding extreme movements that might harm the patient. A sudden movement outside of the range of motion of the patient, a really fast movement, a bad posture, all of them can end in hurting the patient, slowing and even losing the already won benefits of the therapy [54]. For this reason, it is important that in-home rehabilitation systems detect these dangerous movements and alert both the patient and the therapist about them [69].

Saini et al. [60] proposed an unsupervised rehabilitation framework ("Watch Dog") which was one of the first works that considered the implementation of alert systems. Their framework is supposed to provide restrictions so that patients can't exceed limited angles of movement. It helps to ensure that the patient exercising at home won't exercise to higher levels than prescribed, or for more time than necessary. Webster and Celik [24], pointed out that rehabilitation system for elderly care must have some way to detect dangerous situations that may lead to hurting the patient. In their work, they mainly refer to lower limb rehabilitation, which they confirm, must have some way of fall detection and fall risk reduction. This was confirmed by the work of Ejupi et al. [88], where they used Kinect ${ }^{\mathrm{TM}}$ to measure the reaching and stepping reaction time of older people to detect the possibility of falls.

The alert systems developed in the reviewed papers, mostly focused on the detection of compensatory movement of the patient $[25,26,29,54]$ (14\% of total works). As with adaptive difficulty and range of motion, the REWIRE project $[30,31]$ has the best implementation of this feature, going as far as creating different levels of alerts for erroneous movements. When the alert level is small, warnings are shown to the patient, when the level of alert is high, the game session is paused and the therapist is also alerted to take actions.

Despite its major benefits, the importance of alert systems is not reflected by the percentage of works that implemented it $(17 \%)$. Furthermore, automatic alert systems are necessary for the 
adoption of fully unsupervised in-home rehabilitation systems, as the patient's safety is one of the major concerns. Hence, automatic alert systems need to be better studied and developed.

\subsection{Motivational rewards}

Current commercial video-games highly rely on achievements and rewards to keep the player engaged. This feature will not only help in motivating the players but may also allow them to set long-term objectives and a way to remember the milestones that have been reached through the time [89]. Points, rankings, achievements, trophies, discovery of secrets, daily log-in rewards and daily missions are rewarding systems that are proven to keep the players engaged in a game. Moreover, when these features can be shared with others, the players tend to be so motivated that it can generate addiction [90].

Reviewed stroke rehabilitation systems don't seem to implement many of these motivational rewards beside the point system which was implemented in all the reviewed works ( $100 \%$ of total works). This reward system grants a score based on patient's actions and interaction with the game's objects, which represents his/her in-game performance. An exception to this tendency is the work of Sadihov et al. [46], where they have also implemented the reward of achievements and trophies. In their work, they reward the good performance of the patients by giving them 3D buildings, which later can be organized to build their own city. This implementation not only exploits the collector and builder desire of the patients but additionally it gives them a sense of progression, as they can see their city becoming bigger while progressing with their rehabilitation. Increasing motivation is one of the main objectives of gamified systems. Point system is the most basic form of motivational rewards, which was implemented in all the reviewed studies. However, others forms of motivational rewards were only used in only one study (3\%). This represents a gap in the current implementations and opens opportunities for future research on the investigation of the effects and benefits of using more types of motivational rewards.

\subsection{Engagement detection and emotion recognition}

Other features which may be very useful in gamified rehabilitation systems are the ability to automatically detect the engagement and emotion of the patient. Commonly, the emotions (mainly motivation and enjoyment) of the patient are captured by the uses of questionnaires or interviews conducted by the experimenter prior and after the game sessions $[9,18,19,25-29,34,36,39,40$, $42,43,48](50 \%$ of total works). Engagement detection is usually measured by the in-game recorded played time $[18,25,28,32-34,48,53]$ (25\% of total works).

The works with the closest implementation of these features are: Recovery Rapids [32, 33], which presents in-game questionnaires to be answered by the patient, they allow capturing the patient's emotional point of view but this is not made automatically. The project RehabCity [39, 40] includes a form of automatic engagement detection. This system detects what part of the screen the user is looking at during the gameplay, allowing the determination of the visual parts of the interface that are more used by the patient.

Engagement detection that is mainly captured by measuring the in-game recorded playing time of patients has been used in $25 \%$ of total works. However, the time spent in the game cannot fully explain the user's behavior. For this reason, implementations such as the one used in the RehabCity project $[39,40]$ can provide extra information and allow gaining further insight. Capturing the motivation and enjoyment of the patient inside the game might provide beneficial information about the player's experience. Unfortunately, this is performed outside of the game in the reviewed works.

\section{Analysis}

This paper reviewed a total of 28 unique works to determine the important features of in-home stroke rehabilitation systems. Some tendencies were found after analyzing the features. These tendencies are related to the final objective of each feature, the relationship between the features and the current gaps in applying these features.

\subsection{Objective-focused classification groups}


20 features have been identified in this review, and possibly more features will be incorporated in future rehabilitation systems. In order to organize all of these features, it was deemed necessary to classify them by groups to better determine the relationships among them and to establish a foundation for the gamified rehabilitation research community. The criterion selected for this classification is the objective that each feature pursuits; hence, it is called objective-focused classification. After analyzing the features to identify their objectives, four different groups emerged. Although it is important to note that a feature can serve more than one objective. Table 3 presents the groups and their features. The groups of features are explained below:

Rehabilitation-focused. The main objective of the gamified rehabilitation systems is the rehabilitation of the patient. The features in the rehabilitation-focused group are features that enforce the necessary activities that directly help to induce rehabilitation. Usually, a system focuses on one type of rehabilitation such as lower body, upper body or cognitive. In some cases, the system might be focused on treating a subset of the union of those three kinds of rehabilitation. Defining which aspects of the patient's disabilities to be treated is the first step to be taken, then, more rehabilitation features can be implemented. The rehabilitation-focused group includes the following features: Type of Rehabilitation, Feedback, Difficulty, Adaptive Range of Motion and Alert System.

Adoption-focused. Another objective of any developed rehabilitation system is the requirement to be used by patients in real-world conditions. To achieve this objective, the developed system must be functional and usable. The usability aspect becomes more crucial for patients who suffer from disabilities. The way patients interact with the system during the therapy sessions affects the patients' quality recovery and also the affordances of the rehabilitation. Additionally, the adoption of a rehabilitation approach depends on its cost since expensive solutions might not be accessible by health bodies and hospitals. These economic problems are more notorious on in-home situations where the patients want to acquire a rehabilitation system however its cost is a restrictive factor. The adoption-focused group strives to achieve acceptance of the rehabilitation system by both, therapist and patients. The adoption-focused group includes the following features: In-home use, Cost, Patient's Monitoring, Quality of Interaction, Simple Interaction Devices, Adaptive Range of Motion and Alert System.

Motivation-focused. One of the main drawbacks of traditional rehabilitation therapies is the lack of patient's motivation to practice the exercises as frequent as necessary. This is especially important in the cases of the chronic phase of the rehabilitation where the patient starts to lose the will to adhere to the rehabilitation programme. Motivation is one of the main objectives of gamified systems; it drives the patient to do the necessary activities for his rehabilitation. Motivation-focused features are those who make the patient to willingly commit to the therapy programme. The motivation-focused group includes the following features: Meaningful Play, Feedback, Social Interaction, Variety, Quality of Interaction, Familiarity, Focus, Mode of Interaction, Difficulty and Motivational Rewards.

Monitoring-focused. One of the main advantages of integrating computer technologies into rehabilitation therapies is the possibility of monitoring several aspects of the patient's performance. Technology allows capturing data, which might not be easily perceived by the therapist due to restrictions of time and space. For this reason, the monitoring of patients can be enriched with technologies that allow capturing and processing therapy data. The features in the monitoringfocused group can be considered as an aid for the therapist to make the follow up of the patient's progression along the execution of the treatment programme. The monitoring-focused group includes the following features: Patient's Monitoring, Data Analysis, Feedback, Adaptive Range of Motion, Alert System, Engagement Detection and Emotion Recognition. It is important to note that, although each classification group is very well delimited by their objectives, the boundaries of the groups of features are not exclusive. The system features can belong to more than one group. For example, a feature can be a factor that induces motivation for the patients, while helping to monitor their activities. 
Table 3. Objective-focused classification groups and their identified features.

\begin{tabular}{|c|c|c|c|c|}
\hline & \multicolumn{4}{|c|}{ Feature Groups } \\
\hline Features & $\begin{array}{l}\text { Rehabilitation- } \\
\text { Focused }\end{array}$ & Adoption-Focused & Motivation-Focused & Monitoring-Focused \\
\hline In-home use & & * & & \\
\hline Cost & & $*$ & & \\
\hline $\begin{array}{c}\text { Type of } \\
\text { Rehabilitation }\end{array}$ & $*$ & & & \\
\hline Patient's Monitoring & & $*$ & & $*$ \\
\hline Data Analysis & & & & $*$ \\
\hline Meaningful Play & & & $*$ & \\
\hline Feedback & $*$ & & $*$ & $*$ \\
\hline Social Interaction & & & $*$ & \\
\hline Variety & & & $*$ & \\
\hline $\begin{array}{l}\text { Quality of } \\
\text { Interaction }\end{array}$ & & $*$ & $*$ & \\
\hline Familiarity & & & $*$ & \\
\hline Focus & & & $*$ & \\
\hline Mode of Interaction & & & $*$ & \\
\hline Difficulty & $*$ & & $*$ & \\
\hline $\begin{array}{c}\text { Simple Interaction } \\
\text { Devices }\end{array}$ & & * & & \\
\hline $\begin{array}{c}\text { Adaptive Range of } \\
\text { Motion }\end{array}$ & $*$ & $*$ & & $*$ \\
\hline Alert System & $*$ & $*$ & & $*$ \\
\hline $\begin{array}{c}\text { Motivational } \\
\text { Rewards }\end{array}$ & & & $*$ & \\
\hline $\begin{array}{l}\text { Engagement } \\
\text { Detection }\end{array}$ & & & & $*$ \\
\hline Emotion Recognition & & & & $*$ \\
\hline
\end{tabular}

\subsection{The relationships of features within each objective-focused group}

The proposed classification and the identified features led to realize the relationships and correlations between the features belonging to the same objective-focused group. Hence, for each objectivefocused group, the nature and impact of the identified relationships are elaborated. This analysis of inter-group relationships is based on the existing knowledge in the literature and the quantitative evaluations of the reviewed works.

\subsubsection{Adoption-focused relationships}

\section{In-home use, patient's monitoring and alert system}

The relationship among the features of "in-home use", "patient's monitoring" and "alert system" is one of the most prominent relationships captured during the analysis process. After analyzing the features of the group, the following relationship was found: In order to provide the patients and therapists with confidence in using fully unsupervised in-home rehabilitation systems, the patient's monitoring must be enabled, making special focus on alert systems to avoid damage to the patient. This relationship enforces the importance of the alert systems, which in fact, was not extensively addressed in the reviewed researches, as only 5 works (17\% of total works) implemented it. If alert systems become sufficiently intelligent to successfully rectify the patient's movements and to detect and prevent any harmful situation that might cause injury, it can reduce the concerns of using unsupervised rehabilitation systems. Nevertheless, the feasibility and compliance of the in-home fully unsupervised gamified rehabilitation systems need to be tested for several weeks by the patients prior to their professional acceptance $[49,54]$. 
In-home use, cost and simple interaction devices

All of the rehabilitation systems proposed in the reviewed papers were intended to be used as inhome systems. From the analysis of these studies, it was revealed that in-home systems tend to use simple and low-cost hardware. This is confirmed by the fact that 26 out of 28 ( $92 \%$ of total works) of these works used low-cost solutions, while 27 out of 28 (96\% of total works) implemented NUI for the interaction with the system. Hence, this indicates that low-cost and simple hardware is more suitable and affordable for in-home rehabilitation systems of stroke patients.

\subsubsection{Rehabilitation-focused relationships}

Difficulty and adaptive range of motion

After analyzing the features of the rehabilitation-focused group, a relationship between difficulty and adaptive range of motion was identified. Although, in the reviewed works the difficulty is more addressed than the range of motion (67\% vs. $25 \%$ respectively), this can be adjudicated to the fact that the range of motion can be perceived as difficulty $[53,74]$. Because of this similarity, some works that addressed the problem of difficulty did pay attention to the aspect of the range of motion adaptation, which is another problem to be considered. The reviewed works confirmed this assumption; when the authors considered that the range of motion is different from difficulty, they implemented both features in all cases but one (85\%). The difficulty and the adaptive range of motion can be implemented as automatic features, this can be tuned by the in-game parameters in order to increase or decrease the effort exerted by the user.

\subsubsection{Motivation-focused relationships}

Variety, quality of interaction, familiarity, focus and mode of interaction

As explained previously, variety is a very useful feature because it may allow addressing a wider scope of the patients' disabilities. In fact, variety may be a solution to achieve other motivationalfocused features such as quality of interaction, familiarity, focus and mode of interaction. If a wide catalog of games is provided, this makes possible to implement additional features. The reviewed works confirmed this argument as the systems that include variety, with four or more games, have also implement at least two other features. The only work that implemented all the other 4 features has a variety of 9 games [18]. Hence, other motivational-focused features can also be addressed when the variety is implemented.

Finally, another relationship could exist between the features familiarity and quality of interaction, as 8 out of $10(80 \%)$ of the works that implemented familiarity include also the quality of interaction. This means that when patients become familiar with a game and its rules, they perceive it as more intuitive. Therefore, it can be concluded that familiarity leads to intuitiveness, which positively affects the quality of the interaction. Hence, monitoring the targeted patients in order to identify their familiar experiences, helps creating intuitive games which ultimately can lead to a more enjoyable and engaging experience.

\section{Social interaction and motivational features}

Social interaction and motivational features are among powerful motivation-focused features that have been used since many years in commercial video-games. However, while most gamified rehabilitation systems focus on motivation, they had been slow in adopting these powerful motivating features. In fact, all the reviewed works implemented a basic form of motivational rewards, such as the point system that grants a score to some of the in-game actions of the player. Nevertheless, more motivational rewards exist in commercial games such as leaderboards, status, achievements, levels, avatar customization and daily challenges [20,91]. It is interesting to notice that in the reviewed works, only two systems (7\%) implemented social interaction, while only one system (3\%) implemented trophies as another motivational feature apart from score system. Unfortunately, this denotes a lack of interest to consider these features despite its important role in the motivation of the players. With regard to these issues, stroke rehabilitation systems' developers could be inspired from commercial video-games to implement the features that engage the player to practice for long periods of time. 


\subsubsection{Monitoring-focused relationships}

\section{Engagement detection and emotion recognition}

Although these features are included in some works in the form of recording the playing time (Engagement Detection; 25\% of total works), or as questionnaires/interviews after the game sessions (Emotion Recognition; $50 \%$ of total works). Only one study implemented an automated version of this feature (3\% of total works). Capturing the player's emotions in real-time could be very helpful, the game developer would know what parts of the game trigger emotions and enhances the engagement. If these features are recorded simultaneously with the gameplay, this could help in the detection of the game events and the features that affect positively or negatively the motivation of the patient. Hence, the positive aspects can be used to create new games, or reinforce the existing ones, while negative aspects could be avoided or corrected. The main importance of the implementation of automatic capture of engagement detection and emotion recognition is to maximize the motivation of the patient by providing enjoyable digital content in the game.

\subsection{Tendencies and Opportunities}

The analysis of the results of this research review is based on the findings obtained from the literature survey, the quantitative evaluations of the reviewed works and the relationships among the identified features. The objective of this analysis is to state the tendencies and the opportunities for the future directions.

\subsubsection{Tendencies}

Development of simple to use and low-cost solutions for in-home systems

The literature shows that NUIs are convenient for stroke patients due to their limited learning curve. NUIs have been used in $96 \%$ of the reviewed studies, which denotes a preference for using natural interfaces. Based on the important number of works using low-cost hardware ( $92 \%$ of total works), it can be concluded that low-cost solutions are preferred over expensive systems. Finally, although not all of the reviewed works were tested at in-home conditions, they all were aimed or projected to be applicable for in-home rehabilitation. Targeting in-home use with its affordability constraints can be one of the main reasons for which the tendency of using simple low-cost hardware is being considered.

\section{Variety to fulfill other motivation-focused features}

Variety was implemented by $46 \%$ of the reviewed works. When it was present, it was correlated with other motivational-focused features, namely quality of interaction, familiarity, focus and mode of interaction. When variety was implemented with the inclusion of four or more games, at least two of the aforementioned features were also present. Hence, variety is not only useful for its individual advantages, but also for the possibility of allowing the implementation of other features.

\subsubsection{Opportunities for future research}

\section{Integral systems}

Stroke rehabilitation systems can be divided into three main areas: upper-limb, lower-limb and cognitive. All the works reviewed in the scope of this study address the upper-limb rehabilitation. Additionally, $10 \%$ of the studies also consist of lower-limb rehabilitation and the other $10 \%$ are dedicated for cognitive rehabilitation. However, none of the works cover the three main rehabilitation aspects simultaneously. Therefore, an integrated system addressing upper-limb, lowerlimb and cognitive rehabilitation concurrently could have the potential to make a crucial contribution to the gamified therapy.

\section{Data analytics}

In all stroke rehabilitation systems, it is important to perform accurate assessments of the physical and cognitive recovery. Regarding the efficiency of the system, data must be processed and presented to the therapist in a meaningful and useful way, especially for in-home unsupervised systems. Furthermore, real-time information feedback provided by rehabilitation systems enables the therapists to take necessary and immediate actions. In addition, since the experience of the therapists in technology-based rehabilitation systems might be limited, the information must be visualized with simple illustrations. Real-time data analytics and visualization have potential to perform as an 
informative decision-support tool for the therapists. In the reviewed works, only one study, representing $3 \%$ of total works, implemented data analytics but without using real time processing, which is a drawback of this study. Hence, real-time data analytics and visualization is an important opportunity for the development of innovative rehabilitation systems.

\section{Automatic engagement detection and emotion recognition}

Automatic engagement detection and emotion recognition features were merely implemented in one work (each representing 3\% of total studies). Gaining a better understanding of the game events that trigger the player's engagement and emotions, might also provide insights for future game developers in terms of the aspects relating to the users' affection. Positive aspects can be re-used to reinforce a positive experience, while negative aspects can be corrected or avoided. Therefore, including automatic engagement detection and emotion recognition features in the rehabilitation system could play an important role in the collection of valuable information about enhancing the patients' overall gamified experience.

\section{Alert systems}

In order to prevent potential injuries, alert systems are necessary for providing patients and therapists with sufficient level of reliability in using in-home rehabilitation systems. In order to be adopted by therapists and patients, alert systems must be intelligent so that they can rectify the patient's movements, as well as detecting and preventing the situations that might cause injuries. Therefore, given that automatic alert systems are crucial for the adoption of fully unsupervised in-home rehabilitation systems, it is recommended to include this feature in the future development of the research in rehabilitation approaches.

\section{Social interaction and novel motivational features}

Social interaction and motivational features can drive the positive motivation of the patients. Being able to cooperate to overcome collective challenges or participating in a friendly competition can be an appealing feature for a gamified stroke rehabilitation system. The small number of the reviewed works that implemented these features (7\% of total works for social interaction and 3\% for novel motivational features), must not be a demotivating factor to include them in the future research. Moreover, developing these features could represent important opportunities to investigate their impact for the motivation of the patients and the increase of their adherence to the rehabilitation programme.

\subsection{Study Limitations}

The limitations of this study is the selection criteria. The search terms identified a total of 1090 articles, but only 32 articles among them met all the criteria. In addition, it was found that some of those articles are interrelated which led to the analytical review of 28 works only. One of the criteria that limited the number of works was that the papers must include a developed game. This factor reduced the number of the identified articles as many of them focused on analyzing the effect of using off-the-shelf games as gamified post stroke rehabilitation systems. The other limiting criteria were the requirement of using the developed system for in-home therapy and it should allow unassisted use. Those criteria were used to specify the in-home focus of the system. Finally, as a mean of setting a minimum threshold for the quality of the papers, only the systems that are tested by at least one subject and having at least one citation were accepted for this analysis. Unfortunately, this criteria excluded the papers published recently, particularly in 2017.

\section{Conclusions and Future Research}

In order to overcome their disabilities, stroke patients have to practice exercises to regain some of their pre-stroke capabilities. A therapy programme carried out for long periods of time can end up being tiring for the patients, thus reducing their motivation to adhere to rehabilitation programme. To help the patient to stay motivated to perform the rehabilitation exercises, gamified rehabilitation systems have emerged. In order to identify their relevant features, this paper focused on selecting and analyzing the tested gamified upper limb in-home rehabilitation systems for stroke survivors available in the literature between 2009 and 2017. After applying some inclusion criteria, a total of 28 works were selected and analyzed. From this analysis, 20 features were identified. The features were explained and their application in the systems in which they were implemented was detailed. 
After analyzing the selected studies, a classification for grouping the features was established. This proposed classification was based on the objectives of the features, hence it was called objectivefocused classification. By applying this classification, some relationships between features were identified. The relationships of the features were explained by specifying how they are interrelated and the impact of these relationships on gamified stroke rehabilitation systems was presented.

Finally, the identification of the relationships and the analysis of each feature allowed the identification of some tendencies and gaps in the reviewed rehabilitation systems. It was found that there is a tendency to 1) Develop simple to use and low-cost solutions for in-home systems. 2) Use variety, as one of the simplest solutions to fulfill other motivation-focused features. Opportunities for future research were found in the areas of 1) Integral systems addressing lower-limb, upper-limb and cognitive rehabilitation simultaneously. 2) Data analytics and visualization. 3) Automatic engagement detection and emotion recognition. 4) Alert systems. 5) Social interaction and novel motivational features.

It is worth noting that visual analytics is a fundamental feature for in-home rehabilitation systems; it allows the therapist to monitor many parameters of the patient's activities and to take actions to optimize the execution of the therapy programme. Additionally, social interaction could improve the motivation and emotion of the patient as he/she can practice the gamified therapy with other players where collective challenges and performance/competition are the main elements to reinforce the adherence to the programme.

\section{Acknowledgements}

The authors of this paper acknowledge the financial support provided for this research by the National Council of Science and Technology, Mexico (CONACYT).

\section{References}

[1] Jørgensen, H. S., Nakayama, H., Raaschou, H. O., \& Olsen, T. S. Recovery of walking function in stroke patients: The copenhagen stroke study. Archives of Physical Medicine and Rehabilitation, 76(1), 27-32. 1995. doi: http://dx.doi.org/10.1016/S0003-9993(95)80038-7

[2] Donnan, G. A., Fisher, M., Macleod, M., \& Davis, S. M. Stroke. The Lancet, 371(9624), $1612-$ 1623. 2008. doi: http://dx.doi.org/10.1016/S0140-6736(08)60694-7

[3] National Stroke Association. What is a Stroke? Retrieved October, 2017, from http://www.stroke.org/understand-stroke/what-stroke

[4] American Stroke Association. What is a Stroke? Retrieved October, 2017, from http://www.strokeassociation.org/STROKEORG/AboutStroke/AboutStroke_UCM 308529_SubHomePage.jsp

[5] Jørgensen, H. S., Nakayama, H., Raaschou, H. O., Vive-Larsen, J., Støier, M., \& Olsen, T. S. Outcome and time course of recovery in stroke. Part I: Outcome. The Copenhagen stroke study. Archives of Physical Medicine and Rehabilitation, 76(5), 399-405. 1995a doi: http://dx.doi.org/10.1016/S0003-9993(95)80567-2

[6] Jørgensen, H. S., Nakayama, H., Raaschou, H. O., Vive-Larsen, J., Støier, M., \& Olsen, T. S. Outcome and time course of recovery in stroke. Part II: Time course of recovery. The copenhagen stroke study. Archives of Physical Medicine and Rehabilitation, 76(5), 406-412. 1995b. doi: http://dx.doi.org/10.1016/S0003-9993(95)80568-0

[7] Cifu, D. X., \& Stewart, D. G. Factors affecting functional outcome after stroke: A critical review of rehabilitation interventions. Archives of Physical Medicine and Rehabilitation, 80(5), S35S39. 1999. doi: http://dx.doi.org/10.1016/S0003-9993(99)90101-6

[8] O'Sullivan, S. B., \& Schmitz, T. J. Physical Rehabilitation (6th ed.). Pennsylvania, United States: F.A. Davis Company. 2013. ISBN-13: 978-0-8036-2579-2

[9] Jacobs, A., Timmermans, A., Michielsen, M., Plaetse, M. V., \& Markopoulos, P. CONTRAST: gamification of arm-hand training for stroke survivors. CHI '13 Extended Abstracts on Human Factors in Computing Systems, Paris, France. 415-420. 2013. doi: http://dx.doi.org/10.1145/2468356.2468430

[10] Burdea, G. Keynote address: Virtual rehabilitation-benefits and challenges. 1st International Workshop on Virtual Reality Rehabilitation (Mental Health, Neurological, Physical, Vocational) VRMHR (Vol. 2002). 1-11. 2002. 
[11]Lange, B., Flynn, S. M., \& Rizzo, A. Game-based telerehabilitation. Eur J Phys Rehabil Med, 45(1), 143-151. 2009.

[12] Proffitt, R. Home Exercise Programs for Adults With Neurological Injuries: A Survey. The American Journal of Occupational Therapy, 70(3):7003290020p1-7003290020p8. 2016. doi: http://dx.doi.org/10.5014/ajot.2016.019729

[13] Saposnik, G., \& Levin, M. Virtual Reality in Stroke Rehabilitation. A Meta-Analysis and Implications for Clinicians, 42(5), 1380-1386. $2011 . \quad$ doi: http://dx.doi.org/10.1161/strokeaha.110.605451

[14] Teasell, R. W., Foley, N. C., Bhogal, S. K., \& Speechley, M. R. An Evidence-Based Review of Stroke Rehabilitation. Topics in Stroke Rehabilitation. (16th ed.), 1-35. 2016.

[15] Flores, E., Tobon, G., Cavallaro, E., Cavallaro, F. I., Perry, J. C., \& Keller, T. Improving patient motivation in game development for motor deficit rehabilitation. In Proceedings of the 2008 International Conference on Advances in Computer Entertainment Technology, Yokohama, Japan. 381- 384. 2008. doi: https://doi.org/10.1145/1501750.1501839

[16] Lange, B., Flynn, S., \& Rizzo, An Initial usability assessment of off-the-shelf video game consoles for clinical game-based motor rehabilitation. Physical Therapy Reviews, 14(5), 355363. 2009. doi: http://dx.doi.org/10.1179/108331909X12488667117258

[17] Rego, P., Moreira, P. M., \& Reis, L. P. Serious games for rehabilitation: A survey and a classification towards a taxonomy. 5th Iberian Conference on Information Systems and Technologies, 349-354. 16-19 June 2010

[18] King, M., Hijmans, M., Sampson, M., Satherley, J., \& Hale, L. Home-based stroke rehabilitation using computer gaming. New Zealand Journal of Physiotherapy, 40, 129-135. 2012

[19]Ferreira, C., Guimaraes, V., Santos, A., \& Sousa, I. Gamification of stroke rehabilitation exercises using a smartphone. In Proceedings of the 8th International Conference on Pervasive Computing Technologies for Healthcare, Oldenburg, Germany. 282-285. 2014. doi: http://dx.doi.org/10.4108/icst.pervasivehealth.2014.255326

[20] Dithmer, M., Rasmussen, J. O., Grönvall, E., Spindler, H., Hansen, J., Nielsen, G., Dinesen, B. "The Heart Game": Using Gamification as Part of a Telerehabilitation Program for Heart Patients. Games For Health Journal, 5(1), 27-33. 2016. doi: http://dx.doi.org/10.1089/g4h.2015.0001

[21] Hung, Y.-X., Huang, P.-C., Chen, K.-T., \& Chu, W.-C. What Do Stroke Patients Look for in Game-Based Rehabilitation: A Survey Study. Medicine, 95(11), e3032. 1-10. 2016. doi: http://dx.doi.org/10.1097/MD.0000000000003032

[22] Barrett, N., Swain, I., Gatzidis, C., \& Mecheraoui, C. The use and effect of video game design theory in the creation of game-based systems for upper limb stroke rehabilitation. Journal of Rehabilitation and Assistive Technologies Engineering, 3, 2055668316643644. 1-16. 2016. doi: http://dx.doi.org/doi:10.1177/2055668316643644

[23] Lohse, K. R., Hilderman, C. G. E., Cheung, K. L., Tatla, S., \& Van der Loos, H. F. M. Virtual Reality Therapy for Adults Post-Stroke: A Systematic Review and Meta-Analysis Exploring Virtual Environments and Commercial Games in Therapy. PLoS ONE, 9(3), e93318. 1-13. 2014. doi: http://dx.doi.org/10.1371/journal.pone.0093318

[24] Webster, D., \& Celik, O. Systematic review of Kinect applications in elderly care and stroke rehabilitation. Journal of NeuroEngineering and Rehabilitation, 11(1), 1-24. 2014. doi: http://dx.doi.org/10.1186/1743-0003-11-108

[25] Farreny, M. A., Buen, M. C., Aguirrezabal, A., Ferriol, P., Tous, F., \& Alcalde, M. A. Play for health $(\mathrm{P} 4 \mathrm{H})$ : una nueva herramienta en telerehabilitación. Rehabilitación, 50(3), 135-140. 2012. doi: http://dx.doi.org/10.1016/j.rh.2012.01.001

[26] Chen, M.-H., Huang, L.-L., \& Wang, C.-H. Developing a Digital Game for Stroke Patients' Upper Extremity Rehabilitation - Design, Usability and Effectiveness Assessment. Procedia Manufacturing, 3, 6-12. 2015. doi: http://dx.doi.org/10.1016/j.promfg.2015.07.101

[27] Hussain, A., Balasubramanian, S., Roach, N., Klein, J., Jarrassé, N., Mace, M., Burdet, E. SITAR: a system for independent task-oriented assessment and rehabilitation. Journal of Rehabilitation and Assistive Technologies Engineering, 4, 2055668317729637. 1-16. 2017. doi: http://dx.doi.org/10.1177/2055668317729637

[28] Burke, J. W., McNeill, M. D. J., Charles, D. K., Morrow, P. J., Crosbie, J. H., \& McDonough, S. M. Optimising engagement for stroke rehabilitation using serious games. The Visual Computer, 25(12), 1085- 1099. 2009. doi: http://dx.doi.org/10.1007/s00371-009-0387-4

[29] Alankus, G., Lazar, A., May, M., \& Kelleher, C. Towards customizable games for stroke rehabilitation. In Proceedings of the SIGCHI Conference on Human Factors in Computing 
Systems, Atlanta, Georgia, USA. 2113-2122. 2010. doi: https://doi.org/10.1145/1753326.1753649

[30] Borghese, N. A., Pirovano, M., Mainetti, R., \& Lanzi, P. L. An integrated low-cost system for at-home rehabilitation. In Proceedings of the 18th International Conference on Virtual Systems and Multimedia (VSMM '12). 553-556. 2-5 Sept. 2012. doi: https://doi.org/10.1109/VSMM.2012.6365975

[31] Pirovano, M., Mainetti, R., Baud-Bovy, G., Lanzi, P. L., \& Borghese, N. A. Self-adaptive games for rehabilitation at home. 2012 IEEE Conference on Computational Intelligence and Games (CIG). 179-186. 11-14 Sept. 2012. doi: https://doi.org/10.1109/CIG.2012.6374154

[32] Maung, D., Crawfis, R., Gauthier, L. V., Worthen-Chaudhari, L., Lowes, L. P., Borstad, A., Adams, J. Development of recovery rapids-a game for cost effective stroke therapy. In Proceedings of the International Conference on the Foundations of Digital Games. 1-8. 2014. doi: http://dx.doi.org/10.13140/2.1.3968.8643

[33] Liang, J., Fuhry, D., Maung, D., Borstad, A., Crawfis, R., Gauthier, L., Parthasarathy, S. Data Analytics Framework for A Game-based Rehabilitation System. In Proceedings of the 6th International Conference on Digital Health Conference, Montreal, Quebec, Canada. 67-76. 2016. doi: http://dx.doi.org/10.1145/2896338.2896356

[34] Bower, K. J., Louie, J., Landesrocha, Y., Seedy, P., Gorelik, A., \& Bernhardt, J. Clinical feasibility of interactive motion-controlled games for stroke rehabilitation. Journal of NeuroEngineering and Rehabilitation, 12(63), 1-12. 2015. doi: http://dx.doi.org/10.1186/s12984-015-0057-x

[35] Zampolini, M., Todeschini, E., Bernabeu, G. M., Hermens, H., Ilsbroukx, S., Macellari, V., Vollenbroek, M. Tele-rehabilitation: present and future. Annali dell'Istituto superiore di sanità, 44(2), 125-134. 2008

[36] Shah, N., Basteris, A., \& Amirabdollahian, F. Design Parameters in Multimodal Games for Rehabilitation. Games For Health Journal, 3(1), 13-20. 2014. doi: http://dx.doi.org/10.1089/g4h.2013.0044

[37] Matthew, M., Christina, O. C., Linda, K., Ruth, H., Robert, T., Samantha, M., Group, i. c. w. O. s. S. R. The Impact of Moving to Stroke Rehabilitation Best Practices in Ontario. In O. S. Network (Ed.), (pp. 66). 2012

[38] Golby, C., Raja, V., Lewando Hundt, G., \& Badiyani, S. A low cost'activities of daily living'assessment system for the continual assessment of post-stroke patients, from inpatient/outpatient rehabilitation through to telerehabilitation. Successes and Failures in Telehealth 2011. 1-8. 2011

[39] Vourvopoulos, A., Faria, A. L., Ponnam, K., \& Badia, S. B. i. RehabCity: design and validation of a cognitive assessment and rehabilitation tool through gamified simulations of activities of daily living. In Proceedings of the 11th Conference on Advances in Computer Entertainment Technology, Funchal, Portugal. 1-8. 2014. doi: http://dx.doi.org/10.1145/2663806.2663852

[40] Faria, A. L., Andrade, A., Soares, L., \& i Badia, S. B. Benefits of virtual reality based cognitive rehabilitation through simulated activities of daily living: a randomized controlled trial with stroke patients. Journal of NeuroEngineering and Rehabilitation, 13(1), 96. 1-12. 2016. doi: https://doi.org/10.1186/s12984-016-0204-Z

[41] Faria, A. L., Couras, J., Cameirão, M. S., Paulino, T., Costa, G. M., \& i Badia, S. B. Impact of combined cognitive and motor rehabilitation in a virtual reality task: an on-going longitudinal study in the chronic phase of stroke. 11th International Conference on Disability, Virtual Reality and Associated Technologies. 1-10. 2016

[42] Joo, L. Y., Yin, T. S., Xu, D., Thia, E., Chia, P. F., Kuah, C. W. K., \& He, K. K. A feasibility study using interactive commercial off-the-shelf computer gaming in upper limb rehabilitation in patients after stroke. Journal of Rehabilitation Medicine, 42(5), 437-441. 2010. doi: http://dx.doi.org/10.2340/16501977-0528

[43] Lee, M., Pyun, S.-B., Chung, J., Kim, J., Eun, S.-D., \& Yoon, B. A Further Step to Develop Patient-Friendly Implementation Strategies for Virtual Reality-Based Rehabilitation in Patients with Acute Stroke. Physical Therapy, 96(10), 1554-1564. 2016. doi: http://dx.doi.org/10.2522/ptj.20150271

[44] Saposnik, G., Teasell, R., Mamdani, M., Hall, J., McIlroy, W., Cheung, D., Bayley, M. Effectiveness of Virtual Reality Using Wii Gaming Technology in Stroke Rehabilitation. A Pilot Randomized Clinical Trial and Proof of Principle, 41(7), 1477-1484. 2010. doi: http://dx.doi.org/10.1161/strokeaha.110.584979 
[45]Huang, M.-C., Chen, E., Xu, W., \& Sarrafzadeh, M. Gaming for upper extremities rehabilitation. In Proceedings of the 2nd Conference on Wireless Health, San Diego, California. 2011. doi: https://doi.org/10.1145/2077546.2077576

[46] Sadihov, D., Migge, B., Gassert, R., \& Kim, Y. Prototype of a VR upper-limb rehabilitation system enhanced with motion-based tactile feedback. 2013 World Haptics Conference (WHC). 449-454. 14-17 April 2013. doi: http://dx.doi.org/10.1109/WHC.2013.6548450

[47] Paavola, J. M., Oliver, K. E., \& Ustinova, K. I. Use of X-box Kinect gaming console for rehabilitation of an individual with traumatic brain injury: A case report. Journal of Novel Physiotherapies. 1-6. 2013 doi: http://dx.doi.org/10.4172/2165-7025.1000129

[48] Kirk, P., Grierson, M., Bodak, R., Ward, N., Brander, F., Kelly, K., Stewart, L. Motivating Stroke Rehabilitation through Music: A Feasibility Study Using Digital Musical Instruments in the Home. In Proceedings of the 2016 CHI Conference on Human Factors in Computing Systems, Santa Clara, California, USA. 1781-1785. 2016. doi: https://doi.org/10.1145/2858036.2858376

[49] Serradilla, J., Shi, J. Q., Cheng, Y., Morgan, G., Lambden, C., \& Eyre, J. A. Automatic assessment of upper limb function during play of the action video game, circus challenge: validity and sensitivity to change. 2014 IEEE 3nd International Conference on Serious Games and Applications for Health (SeGAH). 1-7. 14-16 May 2014. doi: https://doi.org/10.1109/SeGAH.2014.7067073

[50] Gabrielli, S., Maimone, R., Costa, C., Ascolese, A., Jonsdottir, J., Klein, W., \& Bendersky, G. A Game-Based Solution for In-Home Rehabilitation. Internet of Things. User-Centric IoT: First International Summit, IoT360 2014, Rome, Italy, October 27-28, 2014, Revised Selected Papers, Part I. Cham: Springer International Publishing, 112-117. 2015. doi: http://dx.doi.org/10.1007/978-3-319-19656-5_17

[51]Ferdous, R., Gabrielli, S., \& Maimone, R. Designing Intuitive Web Solutions for Monitoring Patients' Rehabilitation at Home. ICST Trans. Ambient Systems, 2(8), e3. 1-5. 2015. doi: http://dx.doi.org/10.4108/eai.1-12-2015.150712

[52] Langan, J., DeLave, K., Phillips, L., Pangilinan, P., \& Brown, S. H. Home-Based Telerehabilitation Shows Improved Upper Limb Function in Adults with Chronic Stroke: A Pilot Study. Journal of Rehabilitation Medicine, 45(2), 217-220. 2013. doi: http://dx.doi.org/10.2340/16501977-1115

[53] Standen, P. J., Threapleton, K., Connell, L., Richardson, A., Brown, D. J., Battersby, S., Platts, F. Patients' Use of a Home-Based Virtual Reality System to Provide Rehabilitation of the Upper Limb Following Stroke. Physical Therapy, 95(3), 350-359. 2015. doi: http://dx.doi.org/10.2522/ptj.20130564

[54] Wittmann, F., Held, J. P., Lambercy, O., Starkey, M. L., Curt, A., Höver, R., Gonzenbach, R. R. Self-directed arm therapy at home after stroke with a sensor-based virtual reality training system. Journal of NeuroEngineering and Rehabilitation, 13(75). 1-10. 2016. doi: http://dx.doi.org/10.1186/s12984-016-0182-1

[55] Piron, L., Turolla, A., Agostini, M., Zucconi, C., Cortese, F., Zampolini, M., Tonin, P. Exercises for Paretic Upper Limb after Stroke: A Combined Virtual-Reality and Telemedicine Approach. Journal of Rehabilitation Medicine, 41(12), 1016-1020. 2009. doi: http://dx.doi.org/10.2340/16501977-0459

[56] Kang, H.-Y., Lim, S.-J., Suh, H. S., \& Liew, D. Estimating the lifetime economic burden of stroke according to the age of onset in South Korea: a cost of illness study. BMC Public Health, 11, 646-646. 2011. doi: http://dx.doi.org/10.1186/1471-2458-11-646

[57] Kabadi, G. S., Walker, R., Donaldson, C., \& Shackley, P. The Cost of Treating Stroke in Urban and Rural Tanzania: A 6-Month Pilot Study. African Journal of Neurological Sciences, 32(2), 45-53. 2013

[58] Plumb, P., Seiber, E., Dowling, M. M., Lee, J., Bernard, T. J., deVeber, G., Lo, W. D. Out of Pocket Costs for Childhood Stroke: The Impact of Chronic Illness upon Parents' Pocketbooks. $\begin{array}{llll}\text { Pediatric } & \text { neurology, } & \text { 52(1), } & \text { 73-76. }\end{array}$ http://dx.doi.org/10.1016/j.pediatrneurol.2014.09.010

[59] Chien-Yen, C., Lange, B., Mi, Z., Koenig, S., Requejo, P., Somboon, N., Rizzo, A. A. Towards pervasive physical rehabilitation using Microsoft Kinect. 2012 6th International Conference on Pervasive Computing Technologies for Healthcare (PervasiveHealth) and Workshops. 21-24 May 2012

[60] Saini, S., Rambli, D. R. A., Sulaiman, S., Zakaria, M. N., \& Shukri, S. R. M. A low-cost game framework for a home-based stroke rehabilitation system. 2012 International Conference on 
Computer \& Information Science (ICCIS). 55-60. 12-14 June 2012. doi: https://doi.org/10.1109/ICCISci.2012.6297212

[61] Tanaka, K., Parker, J., Baradoy, G., Sheehan, D., Holash, J. R., \& Katz, L. A comparison of exergaming interfaces for use in rehabilitation programs and research. Loading... The Journal of the Canadian Game Studies Association 6(9), 69-81. 2012

[62]Zhang, M., Lange, B., Chang, C.-Y., Sawchuk, A. A., \& Rizzo, A. A. Beyond the standard clinical rating scales: fine-grained assessment of post-stroke motor functionality using wearable inertial sensors. IEEE Engineering in Medicine and Biology Society 2012. 6111-6115. 2012. doi: https://doi.org/10.1109/EMBC.2012.6347388

[63] Laffont, I., Bakhti, K., Coroian, F., van Dokkum, L., Mottet, D., Schweighofer, N., \& Froger, J. Innovative technologies applied to sensorimotor rehabilitation after stroke. Annals of Physical and Rehabilitation $\quad$ Medicine, 57(8), 543-551. 2014. doi: http://dx.doi.org/10.1016/j.rehab.2014.08.007

[64] Proffitt, R., \& Lange, B. Considerations in the Efficacy and Effectiveness of Virtual Reality Interventions for Stroke Rehabilitation: Moving the Field Forward. Physical Therapy, 95(3), 441-448. 2015. doi: http://dx.doi.org/10.2522/ptj.20130571

[65] Omelina, L., Jansen, B., Bonnechere, B., \& Cornelis, J. Serious games for physical rehabilitation: designing highly configurable and adaptable games. In Proceedings of the $9^{\text {th }}$ International Conference on Disability, VirtualReality and Assoc. Technologies, Laval, France. 195-201. 2012

[66]Zimmerman, E. Play as research: The iterative design process. Design research: Methods and perspectives, 2003, 176-184. 2003

[67] Tekinbaş, K. S., \& Zimmerman, E. Rules of play: Game design fundamentals. Cambridge, Ma: The MIT Press. 2004. ISBN: 9780262240451

[68] Rizzo, A. S., \& Kim, G. J. A SWOT Analysis of the Field of Virtual Reality Rehabilitation and Therapy. Presence: Teleoperators and Virtual Environments, 14(2), 119-146. 2005. doi: http://dx.doi.org/10.1162/1054746053967094

[69] Levin, M. F., Weiss, P. L., \& Keshner, E. A. Emergence of Virtual Reality as a Tool for Upper Limb Rehabilitation: Incorporation of Motor Control and Motor Learning Principles. Physical Therapy, 95(3), 415-425. 2015. doi: http://dx.doi.org/10.2522/ptj.20130579

[70] Janssen, H., Ada, L., Bernhardt, J., McElduff, P., Pollack, M., Nilsson, M., \& Spratt, N. J. An enriched environment increases activity in stroke patients undergoing rehabilitation in a mixed rehabilitation unit: a pilot non-randomized controlled trial. Disability and Rehabilitation, 36(3), 255-262. 2014. doi: http://dx.doi.org/10.3109/09638288.2013.788218

[71] Pedraza-Hueso, M., Martín-Calzón, S., Díaz-Pernas, F. J., \& Martínez-Zarzuela, M. Rehabilitation Using Kinect-based Games and Virtual Reality. Procedia Computer Science, 75, 161-168. 2015. doi: http://dx.doi.org/10.1016/j.procs.2015.12.233

[72] Tremblay, J., Bouchard, B., \& Bouzouane, A. Adaptive Game Mechanics for Learning Purposes-Making Serious Games Playable and Fun. In Proceedings of the International conference on Computer Supported Education: session "Gaming platforms for education and reeducation" (CSEDU 2010), vol 2, 465-470. 2010

[73] Aponte, M.-V., Levieux, G., Natkin, S., Difficulty in videogames: an experimental validation of a formal definition. In Proceedings of the 8th International Conference on Advances in Computer Entertainment Technology, Lisbon, Portugal. 1-18. 2011. doi: https://doi.org/10.1145/2071423.2071484

[74] Hocine, N., Gouaïch, A., \& Cerri, S. A. Dynamic Difficulty Adaptation in Serious Games for Motor Rehabilitation. In S. Göbel \& J. Wiemeyer (Eds.), Games for Training, Education, Health and Sports: 4th International Conference on Serious Games, GameDays 2014, Darmstadt, Germany, April 1-5, 2014. In Proceedings. Cham: Springer International Publishing. 115-128. 2014. doi: https://doi.org/10.1007/978-3-319-05972-3_13

[75] Sutoyo, R., Winata, D., Oliviani, K., \& Supriyadi, D. M. Dynamic Difficulty Adjustment in Tower Defence. Procedia Computer Science, 59, 435-444. 2015. doi: http://dx.doi.org/10.1016/j.procs.2015.07.563

[76] Smeddinck, J. D., Mandryk, R. L., Birk, M. V., Gerling, K. M., Barsilowski, D., \& Malaka, R. How to Present Game Difficulty Choices?: Exploring the Impact on Player Experience. In Proceedings of the 2016 CHI Conference on Human Factors in Computing Systems, Santa Clara, California, USA. 5595-5607. 2016. doi: https://doi.org/10.1145/2858036.2858574

[77] Mourato, F., \& Santos, M. P. d. Measuring difficulty in platform videogames. $4 .^{\text {a }}$ Conferência Nacional Interacção humano-computador, 173-180. 2010 
[78] Hagelback, J., \& Johansson, S. J. Measuring player experience on runtime dynamic difficulty scaling in an RTS game. 2009 IEEE Symposium on Computational Intelligence and Games. 4652. 7-10 Sept. 2009. doi: https://doi.org/10.1109/CIG.2009.5286494

[79] Aponte, M.-V., Levieux, G., \& Natkin, S. Measuring the level of difficulty in single player video games. Entertainment Computing, 2(4), 205-213. 2011. doi: http://dx.doi.org/10.1016/j.entcom.2011.04.001

[80] Csikszentmihalyi, M. Flow: The Psychology of Optimal Experience. New York, NY: Harper Perennial. 1991. ISBN: 0060920432

[81] Lee, S.-H., Song, M., \& Kim, J. Towards clinically relevant automatic assessment of upper-limb motor function impairment. 2016 IEEE-EMBS International Conference on Biomedical and Health Informatics (BHI), 148-151. 2016. doi: https://doi.org/10.1109/BHI.2016.7455856

[82] Su, C.-H., \& Cheng, C.-H. Developing and Evaluating Creativity Gamification Rehabilitation System: The Application of PCA-ANFIS Based Emotions Model. Eurasia Journal of Mathematics, Science \& Technology Education, 12(5), 1443-1468. 2016

[83] Choppin, S., Lane, B., \& Wheat, J. The accuracy of the Microsoft Kinect in joint angle measurement. Sports Technology, 7(1-2), 98-105. 2014. doi: http://dx.doi.org/10.1080/19346182.2014.968165

[84] Wang, Q., Kurillo, G., Ofli, F., \& Bajcsy, R. Evaluation of pose tracking accuracy in the first and second generations of microsoft kinect. 2015 International Conference on Healthcare Informatics (ICHI), 380-389. 2015. doi: https://doi.org/10.1109/ICHI.2015.54

[85] Capecci, M., Ceravolo, M., Ferracuti, F., Iarlori, S., Longhi, S., Romeo, L., Verdini, F. Accuracy evaluation of the Kinect v2 sensor during dynamic movements in a rehabilitation scenario, 54095412. 2016. doi: https://doi.org/10.1109/EMBC.2016.7591950

[86] Gradinaru, A., \& Moldoveanu, A. Kinect v2 evaluation for in-home medical rehabilitation scenarios. Romanian Journal of Human-Computer Interaction, 9(1), 1-18. 2016

[87] Otte, K., Kayser, B., Mansow-Model, S., Verrel, J., Paul, F., Brandt, A. U., \& Schmitz-Hübsch, T. Accuracy and reliability of the kinect version 2 for clinical measurement of motor function. PLoS ONE, 11(11): e0166532. 1-17. 2016. doi: https://doi.org/10.1371/journal.pone.0166532

[88]Ejupi, A., Gschwind, Y. J., Brodie, M., Zagler, W. L., Lord, S. R., \& Delbaere, K. Kinect-based choice reaching and stepping reaction time tests for clinical and in-home assessment of fall risk in older people: a prospective study. European Review of Aging and Physical Activity, 13:2. 17. 2016. doi: https://doi.org/10.1186/s11556-016-0162-2

[89] Lameras, P. Essential features of serious games design in higher education. British Journal of Educational Technology, 48(4). 972-994. 2015. doi: http://dx.doi.org/10.1111/bjet.12467

[90] Grund, C. K. How Games and Game Elements Facilitate Learning and Motivation: A Literature Review. GI-Jahrestagung. 1279-1293. 2015

[91] González-Gonzáleza, C. S., Toledo-Delgado, P., Padrón, M., Santos, E., \& Cairós, M. Including gamification techniques in the design of TANGO: H platform. Jurnal Teknologi, 63(3). 77-84. 2013. doi: http://dx.doi.org/10.11113/jt.v63.1958 